\title{
Accidental Exposure to Docetaxel Overdose - Case Report and Review of the Literature
}

\author{
Amr Muhammed* \\ Department of Clinical Oncology and Nuclear Medicine, Sohag University Hospital, Egypt
}

Submission: December 27, 2017; Published: January 05, 2018

*Corresponding author: Amr Muhammed, Department of Clinical Oncology and Nuclear Medicine, Sohag University Hospital, Egypt,

Tel: +2001004849329; Email: amr.muhammed@med.sohag.edu.eg

\begin{abstract}
Since the 1990s, docetaxel plays an expanding role in the treatment of high-risk breast cancer, lung cancer, advanced gastric and metastatic prostate cancer [1,2]. Hundreds of publications have mentioned the diverse range of docetaxel toxicity profile and the increased likelihood of bone marrow suppression, GIT and skin toxicity with dose escalation beyond $100 \mathrm{mg} / \mathrm{m} 2$ [2]. Despite that, very few authors pointed to cases of docetaxel overdose and proper medical intervention in these cases [3]. This publication aims to point at one of the cases of accidental docetaxel overdose secondary to miscalculation at the clinical pharmacy ward and the medical intervention taken with the case.
\end{abstract}

Keywords: Docetaxel overdose; Docetaxel toxicity; Chemotherapy overdose; Taxane toxicity; Taxane overdose

Abbreviations: ANC: Absolute Neutrophil Count; CYP: Cytochrome P Enzymes; D: Day; GIT: Gastrointestinal Tract; SCLC: Small Cell Lung Cancer

\section{Introduction}

Docetaxel is a hydrophilic semisynthetic analogue of paclitaxel, originally, produced from Taxus Baccata's needles. It facilitates the assembly and stabilization of cellular microtubules through blockage of their depolymerization process. This enhanced stability interferes with their essential arrangement during cell cytokinesis leading to arrest the cell cycle [4].

Docetaxel is metabolized and deactivated by CYP 450 enzymes family, namely, 3A4 and 3A5 then excreted mainly into the bile [5]. The efficacy of the docetaxel detoxifying hepatic elimination depends on several factors such as, the genetic polymorphisms of CYP3A, the concomitant use of CYP3A inducers or inhibitors and Pgp inhibitors that affect Pgp, the membrane transport protein of docetaxel inactive products, in biliary canaliculi $[4,6]$.

Although thousands of publications mentioned and discussed docetaxel related toxicity such as BM depression, GIT and skin toxicity especially patients receiving doses beyond $100 \mathrm{mg} / \mathrm{m} 2$, the literature lacks any reports discussing the issue of docetaxel overdose and the proper clinical management of such condition $[2,3]$.

\section{Case Report}

A 53-years-old male, ECOG-Performance status 1, with a history of refractory Stage-IV SCLC failed on Etoposide-Cisplatin, was admitted to the hospital with grade- 3 diarrhoea and fatigue six days post-Docetaxel-Cisplatin infusion. Accidentally, the patient received overdosed docetaxel at $175 \mathrm{mg} / \mathrm{m} 2$, a total of $280 \mathrm{mg}$ on D1, given on 1-hour infusion and dosed cisplatin at $70 \mathrm{mg} / \mathrm{m} 2$, total dose of $110 \mathrm{mg}$, given on 2 -hour infusion post2000 c.c. fluid hydration.

At admission time, his physical examination revealed grade-3 diarrhoea, dehydration and neutropenia 0.4x109/L and grade- 2 mucositis of the GIT. Liver and kidney function tests were unremarkable. He received adequate IV hydration, broad-spectrum antibiotics; levofloxacin $500 \mathrm{mg} / \mathrm{IV} / 24 \mathrm{hr}$ and metronidazole $500 \mathrm{mg} / \mathrm{IV} / 6 \mathrm{hr}$, GC-CSF factor; filgrastim $5 \mu \mathrm{g} /$ $\mathrm{kg} /$ day/SC and other measures against mucositis. Five days post admission, his diarrhoea was controlled, and his ANC rise to $3.5 \times 109 / \mathrm{L}$. he kept under observation for another 5 days then discharged from the hospital.

\section{Discussion}

Docetaxel is a hydrophilic semisynthetic analogue of paclitaxel is produced from Taxus Baccata's needles. It produces its pharmacological action through stabilization of cellular microtubules leading to cell cycle arrest during mitosis. Thus, docetaxel toxicity and side effect profile are commonly related to tissues with rapid turnover; bone marrow, skin and gut mucosa. 
We described a case of accidentally miscalculated docetaxel dose, given in docetaxel/cisplatin combination, in 53-years old male patient with a history of SCLC failed on first-line Etoposide/Cisplatin. He developed grade-3 diarrhoea, grade- 2 buccal mucositis, and neutropenia at $0.4 \times 109 / \mathrm{L}$. The patient was hospital admitted and received adequate fluid hydration, broad-spectrum antibiotics and hemopoietic growth factor till improvement and discharge.

Till now, no antidote to docetaxel overdose or a predefined standard of care management to cases with overdose. Thus, monitoring the vital signs, adequate hydration, broad-spectrum antibiotics, GC-CSF and other symptoms directed supportive measures remain the only possible guide for dealing with these patients.

\section{Conclusion}

Although docetaxel overdose is a rare medical condition to be seen in current practice, it is still a serious medical condition that needs to be dealt with extreme caution. Since no antidote has been identified to such condition, supportive treatment based on symptoms and guards against neutropenia are the best of care in current practice.

In this case, the early attention to the patient clinical condition, adequate intervention through monitoring of vital signs, enough hydration, use of broad-spectrum antibiotics and GC-CSF factor were enough intervention to facilitate early recovery.

Following this accidental docetaxel-overdose, new restrictions were implemented in the clinical pharmacy and drug preparation unit and chemotherapy ward to prevent such accidents from being happened again.

\section{References}

1. Andersson M, Lidbrink E, Bjerre K, Wist E, Enevoldsen K, et al. (2011) Phase III randomized study comparing docetaxel plus trastuzumab with vinorelbine plus trastuzumab as first-line therapy of metastatic or locally advanced human epidermal growth factor receptor 2-positive breast cancer: the HERNATA study. J Clin Oncol 29(3): 264-271.

2. SANOFI, Taxotere $160 \mathrm{mg} / 8 \mathrm{ml}$ concentrate for solution for infusion. The electronic Medicines Compendium (eMC) 29: e1.

3. Vodovar D, Mongardon N, Moachon L, Arnaout M, Beuzeboc P, et al. (2011) Severe docetaxel overdose induced by pharmacokinetic interaction with dronedarone. J Clin Oncol 29(24): e694-e695.

4. Vigano AL, Gianni L, Garassino M, van Halteren H, Sessa C (2012) Clinical Pharmacology of Anti-Cancer Agents. In: Vigano AL, et al. (Eds.), ESMO Handbook Series 1: 93-99.

5. Baker SD, Sparreboom A, Verweij (2006) Clinical pharmacokinetics of docetaxel: recent developments. Clin Pharmacokinet 45(3): 235-252.

6. Marre F, Sanderink GJ, de Sousa G, Gaillard C, Martinet M, et al. (1996) Hepatic biotransformation of docetaxel (Taxotere) in vitro: involvement of the CYP3A subfamily in humans. Cancer Res 56(6): 1296-1302. 